\title{
Towards a more accurate shrinkage modeling of lightweight and infra-lightweight concrete
}

\author{
Sebastián Labbé ${ }^{\mathrm{a}, \mathrm{c}}$, Mauricio Lopez ${ }^{\mathrm{a}, \mathrm{b}, *}$ \\ ${ }^{a}$ Department of Construction Engineering and Management, School of Engineering, Pontificia Universidad Católica de Chile, Santiago, Chile \\ ${ }^{\mathrm{b}}$ Center for Sustainable Urban Development (CEDEUS), Pontificia Universidad Católica de Chile, Vicuña Mackenna 4860, Casilla 306, Correo 22, Santiago, Chile \\ ${ }^{\mathrm{c}}$ Institute of Concrete Structures and Building Materials, Karlsruhe Institute of Technology, Karlsruhe, Germany
}

\section{H I G H L I G H T S}

- Insulating structural concrete containing expanded clay and glass are produced and tested.

- A mathematical method for extrapolating experimental shrinkage is applied.

- Shrinkage models (ACI \& fib) are calibrated for infra LW and LW concrete.

- Mixes are suitable for insulating \& structural applications in low rise buildings.

\section{Keywords:}

Ultra-lightweight concrete

Infra-lightweight concrete

Internal curing

Expanded clay

Expanded glass

Foamed glass

CEB model

ACI model

\begin{abstract}
A B S T R A C T
Infra lightweight concrete (ILWC) has gained importance in recent years because of its thermal insulation properties; nonetheless, the potential structural applications of these concretes are restrained because the shrinkage of these concretes is not accurately estimated by current prediction models, specifically those in ACI 209.2R 08. The aim of this study is to adjust the prediction models of this phenomenon in lightweight concretes (LWC) through the calibration of existing models by means of statistical analysis of the models included in ACI 209.2R 08 and the fib. Calibration constants and corrections for the predic tion models were found for adjusting the prediction models to LWC and ILWC, achieving $R^{2}$ values of 0.94 and 0.98 , respectively. Based on these results, further research on how porosity, water migration, and other lightweight aggregate properties affect the evolution of shrinkage in LWC should be performed to upgrade prediction models.
\end{abstract}

\section{Introduction}

Infra lightweight concrete (ILWC) has shown in recent years to be a construction material that can provide both structural resis tance and thermal insulation capabilities to buildings, in addition to being a more sustainable material when recycled expanded glass is used as lightweight aggregate [ $\left.\begin{array}{ll}1 & 6\end{array}\right]$. Regarding this, the structural performance of these materials is yet to be fully under stood, as issues such as increased deformations due to shrinkage $\left[\begin{array}{ll}2,7 & 10\end{array}\right]$ still pose a significant barrier to the durability and serviceability of these concretes.

\footnotetext{
* Corresponding author at: Department of Construction Engineering and Management, School of Engineering, Pontificia Universidad Católica de Chile, Santiago, Chile.

E-mail address: mlopez@ing.puc.cl (M. Lopez).
}

There have already been some approaches on how to predict shrinkage of lightweight concrete (LWC) [8], and this work was already adopted in the newest fib model for creep and shrinkage [11]; nonetheless, this research was based on the performance of LWC using expanded clay. ILWC, such as that using expanded glass, has drastically different absorption, aggregate intrinsic strength, and density, which can lead to even greater prediction problems. Additionally, the LWC that was investigated by Kvitsel had a short prewetting time during mixing, mainly because it has been docu mented in European literature that long prewetting time may also bring some negative effects in the long term, such as the increase in the fresh density, which in some cases contributes to drying shrinkage, and the reduction in freeze and fire resistance [12,13]. Nonetheless, prewetting for internal curing can cause an expansion in basic shrinkage in early ages, which can reduce the amount of total shrinkage, provide the cement paste with a steady water 
source, making an impact on the evolution of drying creep by delaying drying of the paste; and help the hydration of the Interfa cial Transition Zone (ITZ) because of the release of the water con tent of the saturated lightweight aggregate (LWA) [7,8,14 18].

Most prediction models consider the strength of the concrete as the main parameter that determines the long term shrinkage behavior of the concrete. After the work done by Kvitsel, only fib uses the unit weight [11] as a parameter to correct the prediction for lightweight mixtures. For the present research, the chosen prediction models are ACI from ACI 209 [19], and FIB2010. Both models are currently employed in model codes and derive their equations from databases that include lightweight concrete mixtures.

Another promising approach to address the mechanical proper ties of LWC is phase models, as a decoupling of the aggregate and cement paste can be performed because of the nature of LWC, where the influence on the mechanical behavior of the ITZ is not as important because this zone is considerably denser and has sim ilar characteristics to the cement matrix [20,21]. It has also been found that in some LWA with more porous and weaker external layers, the ITZ is even denser and has better bonding with the aggregates [22].

Studies have shown $[23,24]$ that most of the shrinkage occurs in the matrix phase (cement paste) of the concrete, with the aggre gates being an "inert phase" that restrict the volumetric changes in the concrete itself, reducing the shrinkage $[25,26]$. For that same reason, if the aggregates are not stiff enough (lightweight aggre gates) or shrink over time (sedimentary rocks), they would not restrain the shrinkage of the cement paste as well as conventional aggregate [27]. The idea of decoupling the effect has not been used in prediction models because the models centered more on treat ing the concrete as a homogenous material with a certain rate of diffusion (time function) and an ultimate shrinkage value.

The purpose of this research was to conduct an exploratory investigation of long term deformations of infra lightweight concrete (ILWC), to analyze the performance of prediction models proposed in ACI 209.2R 08 and fib regarding model accuracy and to better understand shrinkage by means of calibrating such models with the experimental data. With this objective, shrinkage was studied following the design requirements of ILWC used for thermal insulation, considering internal curing by means of prewet ting of the LWA. Specifically, shrinkage was monitored for approx imately 90 days for three mixtures, one LWC using expanded clay (EC), one ILWC using expanded glass (EG), one normal weight concrete (NWC) using normal weight aggregate (NWA) as a refer ence for estimating the accuracy of the model.

\section{Materials and methods}

ASTM Type I ordinary Portland cement (OPC), with a specific gravity of 3.16 and a Blaine fineness of $360\left[\mathrm{~m}^{2} / \mathrm{kg}\right]$, produced in Chile, was used in this study. The main properties are shown in Table 1. Different aggregates were used in this study to experimen tally quantify the effect of using lightweight aggregates on the

Table 1

Cement Properties [29].

\begin{tabular}{ll}
\hline Physical Properties & \\
\hline Density $\left[\mathrm{kg} / \mathrm{m}^{3}\right]$ & 3,160 \\
Blaine Fineness $\left[\mathrm{cm}^{2} / \mathrm{g}\right]$ & 3,600 \\
Initial Setting Time [hh:mm] & $1: 50$ \\
Final Setting Time [hh:mm] & $3: 40$ \\
Chemical Properties & \\
Insoluble Residue [\%] & 0.3 \\
Loss on Ignition [\%] & 2.4 \\
$\mathrm{SO}_{3}[\%]$ & 3.1 \\
\hline
\end{tabular}

shrinkage behavior of concrete. The aggregates were normal weight aggregates from Chile, lightweight expanded clay from Spain, and lightweight expanded glass from Canada (see Table 2).

The LWAs were submerged for $72 \mathrm{~h}$, and the absorption was obtained according to ASTM C1761 [28].

The mixture designs were based on the methodology developed by Videla and López [30], where lightweight concrete is conceived as a two phase material composed of a cementitious matrix (i.e., OPC, water, HRWR, and entrapped air) and the aggregate ratio was kept constant, at 70\% by volume, for both lightweight mixture designs. The water to cement ratio $(\mathrm{W} / \mathrm{C})$ by mass was 0.4 for most of the mixture designs, except for the mixtures with lightweight expanded glass, in which the $\mathrm{W} / \mathrm{C}$ was 0.5 . The mixture propor tions and names for each batch are shown in Table 3:

All the batches were produced in an 80 liter vertical axis mixer. Expanded clay and expanded glass aggregates were immersed in water for $72 \mathrm{~h}$ and drained in No. 50 and No. 200 sieves before mix ing. The moisture content at the time of batching was considered by adjusting the water and aggregate dosages. Fifteen $100 \times 200 \mathrm{~mm}$ cylindrical specimens were cast for each batch for mechanical and drying shrinkage testing, two $100 \times 100 \times 300 \mathrm{~mm}$ prismatic specimens were cast for dynamic elastic and shear modulus tests and two $1 \times 1 \times 12$ in. prismatic specimens were cast for drying shrinkage tests. The concrete specimens were prepared according to ASTM C192 [31].

The specimens were left in their molds for $24 \mathrm{~h}$ and immersed in water at $20( \pm 1)^{\circ} \mathrm{C}$ for 7 days after demolding. Then, all the spec imens were stored in the drying chamber at $22( \pm 1){ }^{\circ} \mathrm{C}$ and $50( \pm 3) \%$ R.H., until the age of testing.

The compressive strength, static elastic modulus, and dynamic elastic modulus were measured at 7, 28 and 90 days of age. Both the compressive strength and static elastic modulus were mea sured using three $100 \times 200 \mathrm{~mm}$ cylindrical specimens, and the measurements followed the guidelines of ASTM C39 and C469 $[32,33]$. The dynamic elastic modulus was measured following ASTM C215 [34], which calculates the dynamic elastic modulus through the measurement of the resonant frequencies.

After 28 days, six $100 \times 60 \mathrm{~mm}$ cylindrical specimens saw cut from two $100 \times 200 \mathrm{~mm}$ specimens were used to measure the thermal conductivity and electrical resistivity. The permeability was classified using the method of Spragg et al. [35], which classi fies it through the measurement of the electrical resistivity of saturated samples, while the thermal conductivity was measured using the hot disk method (TPS1500), which uses a transient tech nique that estimates the thermal conductivity $(\lambda)$ of materials. Additionally, the oven dry density was measured according to ASTM C567 [36].

Drying shrinkage was measured using two different methods. One method followed the standard test method for drying shrink age according to ASTM C596 [37], which employed a length comparator and prismatic $1 \times 1 \times 12$ in. specimens. The other method used demountable mechanical gage (DEMEC) points, which were embedded in $100 \times 200 \mathrm{~mm}$ cylindrical specimens at a spacing of $152 \mathrm{~mm}$ on opposite sides. Three DEMEC readings were taken from each specimen, totaling 9 for each concrete mix and averaged for determining the total time dependent strain.

The measurement of shrinkage using different effective speci men thicknesses is necessary to calculate the ultimate shrinkage strain of the specimens to extrapolate the data for a more precise calibration as done by Bažant and Donmez [38].

\section{Experimental results}

Concrete compressive strength varied widely among the three types of concrete due to several factors, including the mixture 
Table 2

Properties of Aggregates.

\begin{tabular}{|c|c|c|c|c|c|c|}
\hline \multirow[t]{2}{*}{ Property } & \multicolumn{2}{|c|}{ Expanded Clay (EC) } & \multicolumn{2}{|c|}{ Expanded Glass (EG) } & \multicolumn{2}{|c|}{ Normal weight aggregate (NWA) } \\
\hline & Fine & Coarse & Fine & Coarse & Fine & Coarse \\
\hline Type & Siliceous & Siliceous & Siliceous & Siliceous & Siliceous & Siliceous \\
\hline Form & Crushed & Smooth/Rounded & Rounded & Rounded & Irregular/Crushed & Irregular/Crushed \\
\hline Texture & Porous & Porous & Porous & Porous & Rough/Smooth & Rough/Dense \\
\hline Maximum size [mm] & 2.36 & 4.75 & 2.0 & 8.0 & 4.75 & 12.70 \\
\hline SSD Density $\left[\mathrm{kg} / \mathrm{m}^{3}\right]$ & 1206 & 1079 & 742.7 & 464.7 & 2699 & 2701 \\
\hline Dry Density $\left[\mathrm{kg} / \mathrm{m}^{3}\right]$ & 1003 & 886 & 602.2 & 353.54 & 2675 & 2685 \\
\hline Absorption $72 \mathrm{~h}[\%]$ & 20.2 & 21.8 & 54.0 & 30.5 & 0.9 & 0.6 \\
\hline Fineness Modulus & 2.90 & 5.74 & 2.27 & 5.17 & 3.81 & 5.99 \\
\hline \multicolumn{7}{|c|}{ Aggregate proportion by mass [\%] } \\
\hline EC & 56.7 & 43.3 & - & - & - & - \\
\hline EG & - & - & 76.4 & 23.6 & - & - \\
\hline NWA & - & - & - & - & 54.1 & 45.9 \\
\hline
\end{tabular}

Table 3

Mixture proportions of concretes.

\begin{tabular}{|c|c|c|c|c|c|c|}
\hline Mixture & OPC $\left(\mathrm{kg} / \mathrm{m}^{3}\right)$ & Water $\left(\mathrm{kg} / \mathrm{m}^{3}\right)$ & Aggregate $\left(\mathrm{kg} / \mathrm{m}^{3}\right)$ & HRWA $\left(\mathrm{g} / \mathrm{m}^{3}\right)$ & $\mathbf{W} / \mathbf{C}$ & Aggregate Volume \\
\hline NWC (NWA) & 562.50 & 225 & 1584.9 & - & 0.4 & 0.59 \\
\hline LWC (EC) & 390 & 156 & 804.1 & 780 & 0.4 & 0.70 \\
\hline ILWC (EG) & 401 & 201.4 & 493.0 & 802 & 0.5 & 0.70 \\
\hline
\end{tabular}

proportions and constituentś properties. For instance, the water to cement ratios and the paste to aggregate ratios are not the same for the three mixtures. In addition, the NWC had a relatively high compressive strength, normal elastic modulus and density, very low permeability and relatively high thermal conductivity, as shown in Tables 4 and 5.

The LWC had a density of only $57 \%$ of that of the NWC while the thermal conductivity was slightly below $30 \%$ of that of the NWC. The permeability of LWC was classified as low. The LWC had a lower compressive strength and an elastic modulus approximately one third of that of the NWC.

The ILWC had a density of only $42 \%$ of that of the NWC, while the thermal conductivity was $18 \%$ of that of the NWC. The perme ability was classified as moderate. The ILWC had a low compres sive strength and an elastic modulus only $15 \%$ of that of the NWC.

It is worth noting that the compressive strength gains between 7 and 28 days of the LWC and ILWC are small, demonstrating that the concrete failure is not explained by the strength of the cement paste given by the $\mathrm{W} / \mathrm{C}$ and cement hydration but mainly by the intrinsic strength of the LWA. This is known as the ceiling strength of the LWA [17]. The relatively small increase or even decrease in the elastic modulus and compressive strength over time can be caused by the early age drying induced in the specimens, as seen previously [39 41]. These losses were explained as the result of the strain induced by the fast drying of the outermost layer of the specimens, which causes micro cracking, limits the cement hydration and therefore produces inferior mechanical properties.

The mass variation during shrinkage testing was highly depen dent on the mixture type and specimen $\mathrm{V} / \mathrm{S}$ ratio. For instance, for the cylindrical specimens $(V / S=20 \mathrm{~mm})$, the 90 day average mass loss of the NWC, LWC and ILWC was $0.97 \%, 8.64 \%$, and $14.11 \%$, respectively. The important increase in the mass loss of the two lightweight mixtures has been observed before $[2,8]$ and is mainly explained by the high amount of absorbed water in the LWA during the 72 hour prewetting process (see Tables 3 and 4). As expected, the prismatic specimen $(V / S=6.08 \mathrm{~mm})$ showed higher mass loss due to the relatively larger drying surface. For the LWC and ILWC specimens, the 90 day mass loss was $10.26 \%$ and $16.10 \%$, respectively.

The average shrinkage for the cylindrical specimens $(V / S=20 \mathrm{~mm})$ was calculated from six measurements made on
Table 4

Mechanical Properties.

\begin{tabular}{lllll}
\hline Mixture & $\begin{array}{l}\text { Density } \\
\left(\mathbf{k g} / \mathbf{m}^{3}\right)\end{array}$ & $\begin{array}{l}\text { Compressive } \\
\text { Strength }(\mathbf{M P a})\end{array}$ & $\begin{array}{l}\text { Static Elastic } \\
\text { Modulus (GPa) }\end{array}$ & \\
\hline NWC & 7 days & 2428 & 40.5 & 34.9 \\
& 28 days & 2414 & 59.1 & 33.0 \\
LWC & 7 days & 1428 & 20.6 & 9.2 \\
& 28 days & 1346 & 22.5 & 10.4 \\
ILWC & 7 days & 1051 & 10.1 & 5.2 \\
& 28 days & 973 & 7.5 & 5.4 \\
\hline
\end{tabular}

three specimens and is shown in Fig. 1. The 90 day average shrink age of the NWC, LWC and ILWC was $549 \mu \varepsilon, 709 \mu \varepsilon$ and $897 \mu \varepsilon$, respectively. As expected, the ILWC mixture (EG) showed the highest shrinkage among all the mixtures, and the NWC showed the lowest shrinkage. Nevertheless, the shrinkage rates of the three mixtures were different. The early age shrinkage of the LWC was greater than that of the ILWC up to approximately 30 days of drying when both reached similar shrinkage values. After 50 days, the data suggest that the shrinkage rate of the LWC and NWC mixtures tends to decrease, while that of the ILWC does not show such deceleration during the 90 day period, leading to larger shrinkage values at 90 days of drying.

The 90 day shrinkage of the LWC was 7\% larger than that reported in the work of van der Wegen and Bijen [42] in a LWC mixture with similar density and mechanical properties. In addi tion, the 90 day shrinkage of the ILWC was 55\% lower than that reported at 180 days by Breit [3] in an expanded glass mixture tested under comparable conditions.

As a standard deviation, the definition proposed in the work of Wedding et al. [43] was used, obtaining $41.8 \mu \varepsilon$ for the NWC, 33.3 $\mu \varepsilon$ for the LWC and $36.8 \mu \varepsilon$ for the ILWC as follows:

$S \quad\left[\frac{1}{n N \quad 2} \sum_{r}^{n} \sum_{i=1}^{N}\left(\begin{array}{ll}\varepsilon_{i, r} & \overline{\varepsilon_{r}}\end{array}\right)^{2}\right]^{\frac{1}{2}}$

where $\overline{\varepsilon_{r}}$ is the mean shrinkage for a period $t_{r}, \varepsilon_{i, r}$ is the shrinkage of the specimen in a period $t_{r}, N$ is the total number of specimens and $n$ is the total number of periods. 
Table 5

Physical Properties.

\begin{tabular}{|c|c|c|c|c|}
\hline Mixture & Resistivity ( $\Omega-\mathrm{cm})$ & ASTM Permeability (Spragg et al.) & Oven-Dry Density $\left(\mathrm{kg} / \mathrm{m}^{3}\right)$ & Thermal Conductivity $(\mathrm{W} / \mathrm{mK})$ \\
\hline NWC & 22.94 & Very Low & 2220 & 2.10 \\
\hline LWC & 17.36 & Low & 1127 & 0.76 \\
\hline ILWC & 10.13 & Moderate & 790 & 0.44 \\
\hline
\end{tabular}

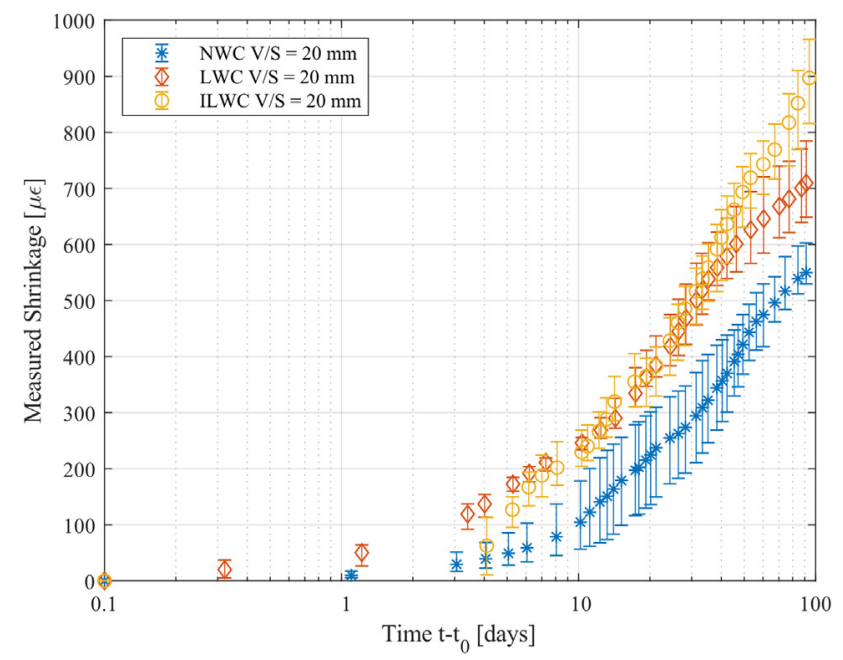

Fig. 1. Average shrinkage of $100 \times 200 \mathrm{~mm}$ NWC, LWC and, ILWC specimens.

\subsection{Comparison of models}

For the ACI [19] and FIB2010 [11] models, the following proper ties shown in Table 6 were considered to predict the behavior of the tested mixtures:

The comparison between the experimental results and the shrinkage model estimates of the NWC, LWC and ILWC mixtures are shown in Fig. 2. The experimental data are shown as the mean and range of the measured values. Because the last experimental results were taken after at least 90 days of drying, Tables 7 and 8 present measured and predicted shrinkage at that age. These tables also present the predicted values at 40 years, which represent the ultimate shrinkage values. The data in the first row represent the measured values; the next three rows are the predicted values for each model.

It can be observed that the shrinkage rate is well represented by the two models when estimating the shrinkage of the NWA. How ever, the shrinkage rates of the two models do not represent well the phenomena observed for the two lightweight concrete mixtures. Both models represent relatively well the shrinkage rate of the LWC up to 20 days of drying but underestimate this rate later, leading to relevant underestimates of the shrinkage values after 30 days of dry ing. None of the models represent the shrinkage rate of the ILWC properly, leading to underestimates after 90 days of drying.

For better evaluation of the performance of each model, a coef ficient of variation $\bar{\omega}_{j}$ was calculated. This coefficient represents the percentage of the total deviation of the model in relation to given measurements. This was defined by Bažant and Baweja [44] as follows:

$\bar{\omega}_{j} \quad \frac{s_{j}}{\overline{\overline{\varepsilon_{j}}}} \quad \frac{1}{\varepsilon_{j}}\left[\frac{1}{1} n \sum_{i 1}^{n}\left(w_{i j} \Delta_{i j}\right)^{2}\right]^{\frac{1}{2}}$

In which

$\overline{\varepsilon_{j}} \quad \frac{1}{n} \sum_{i=1}^{n} w_{i j} \varepsilon_{i j} \quad w_{i j} \quad \frac{n}{n_{d} n_{1}}$
Table 6

Properties of each mix for shrinkage prediction models.

\begin{tabular}{|c|c|c|c|}
\hline Property & NWC & LWC & ILWC \\
\hline Cement Type & $\begin{array}{l}\text { Type I Portland } \\
(\mathrm{ACI}), \mathrm{N} \& \mathrm{R}(\mathrm{CEB})\end{array}$ & $\begin{array}{l}\text { Type I Portland } \\
(\mathrm{ACI}), \mathrm{N} \& \mathrm{R}(\mathrm{CEB})\end{array}$ & $\begin{array}{l}\text { Type I Portland } \\
\text { (ACI), N\&R (CEB) }\end{array}$ \\
\hline $\mathrm{W} / \mathrm{C}$ & 0.4 & 0.4 & 0.5 \\
\hline $\begin{array}{l}\text { Cement content } \\
{\left[\mathrm{kg} / \mathrm{m}^{3}\right]}\end{array}$ & 562.5 & 390 & 401 \\
\hline $\begin{array}{r}\text { Fine aggregate } \\
\text { fraction [\%] }\end{array}$ & 48.82 & 63.36 & 89.43 \\
\hline $\mathrm{A} / \mathrm{C}$ & 2.82 & 2.06 & 1.37 \\
\hline $\mathrm{V} / \mathrm{S}[\mathrm{mm}]$ & 20 & $20-6.08$ & $20-6.08$ \\
\hline $\begin{array}{l}\text { Dry bulk density } \\
{\left[\mathrm{kg} / \mathrm{m}^{3}\right]}\end{array}$ & 2220.2 & 1127.4 & 789.7 \\
\hline Air content & 2.5 & 2.5 & 2.5 \\
\hline Slump [mm] & 75 & 75 & 75 \\
\hline Curing time [days] & 7 & 7 & 7 \\
\hline$E_{7}[\mathrm{GPa}]$ & 34.9 & 9.2 & 5.2 \\
\hline$f_{c}^{\prime} 7$ days [MPa] & 40.5 & 20.6 & 10.1 \\
\hline$E_{28}[\mathrm{GPa}]$ & 33.0 & 10.4 & 5.4 \\
\hline$f_{c}^{\prime} 28$ days $[\mathrm{MPa}]$ & 59.1 & 22.5 & 7.5 \\
\hline $\begin{array}{l}\text { Average curing } \\
\text { temperature } \\
{\left[{ }^{\circ} \mathrm{C}\right]}\end{array}$ & 22 & 22 & 22 \\
\hline $\begin{array}{l}\text { Relative humidity } \\
\text { [\%] }\end{array}$ & 50 & 50 & 50 \\
\hline
\end{tabular}

where $\varepsilon_{i j}$ are the measured values (labeled by subscript $i$ ) of the shrinkage or creep in the dataset $j$, nis the number of all the data points in the dataset number $j, \Delta_{i j}$ is the deviation of the value given by the model from the measured value, $w_{i j}$ are the weights assigned to the data points, $n_{d}$ is the number of decades on the logarithmic time scale spanned by the measured data in dataset number $j$, and $n_{1}$ is the number of data points in the decade to which the data point $i$ belongs.

The weight assigned to a data point in a decade on the logarith mic scale is taken as inversely proportional to the number $n_{1}$ of data points in that decade, and the weights are normalized as follows:

$\sum_{i} w_{i j} n$

The overall coefficient of variation used to compare the perfor mance of the models is then defined as follows:

$\bar{\omega}_{\text {all }} \quad\left[\frac{1}{N} \sum_{j=1} \bar{\omega}_{j}^{2}\right]^{\frac{1}{2}}$

where $N$ is the number of datasets in the bank [44]. This method was slightly modified by just using $w_{i j}=1$ because of the short time span of the tests performed.

Table 7 shows the measured and estimated 90 day shrinkage values for the three concrete mixtures studied. It also shows the coefficient of variation in $\bar{\omega}_{\text {all }} \%$ for the LWC, as defined by Bažant [44] and the estimated ultimate shrinkage values of each of the models.

The best shrinkage estimates for the NWC, LWC and ILWC are from FIB2010 at 90 days. In fact, those estimates were only $0.2 \%$ (overestimated), 7.2\% (underestimated) and 7.1\% (overestimated) different from the measured shrinkage values for the NWC, LWC 

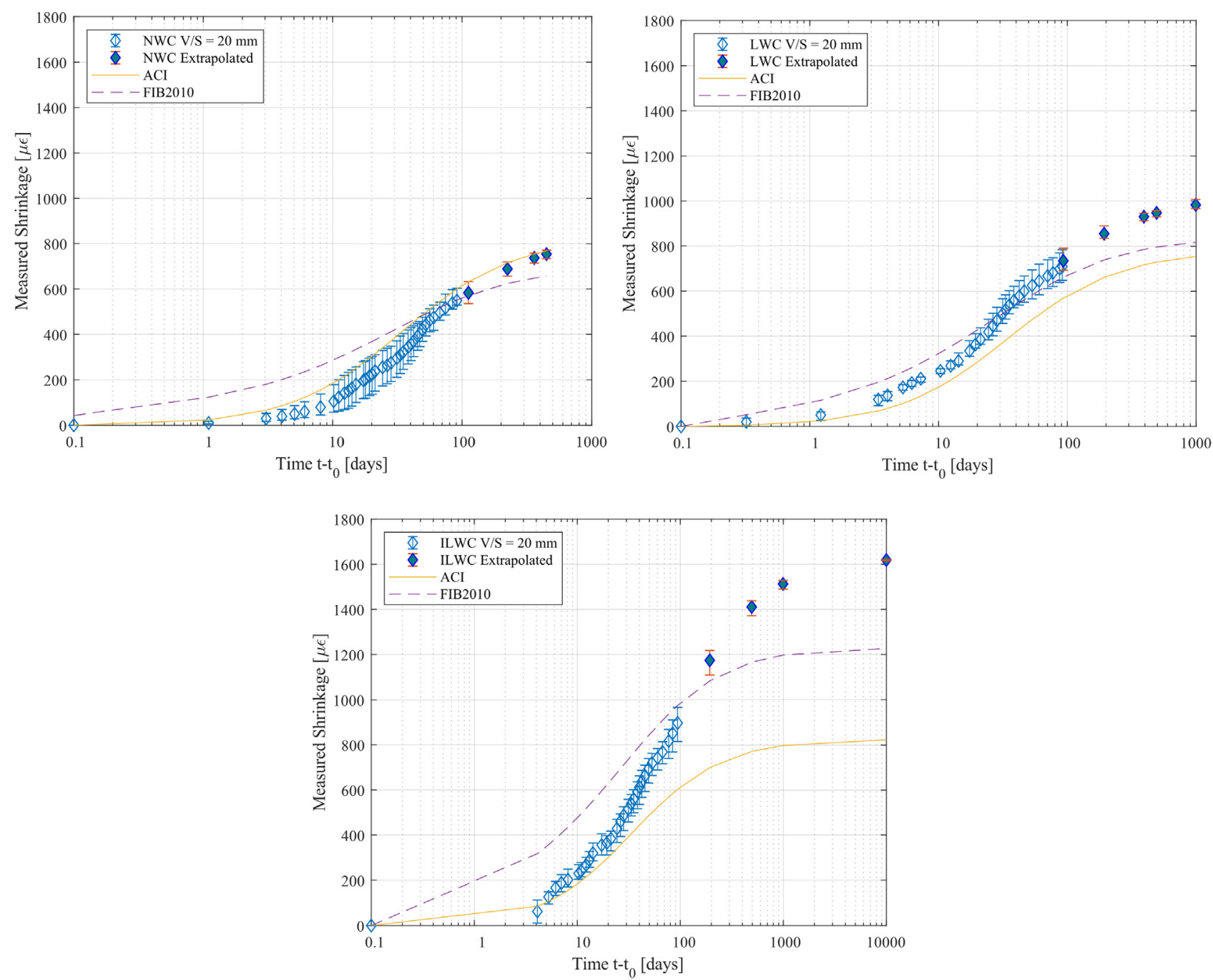

Fig. 2. Comparisons of the measured and model-estimated shrinkage of (a) NWC, (b) LWC and (c) ILWC for V/S $=20 \mathrm{~mm}$.

Table 7

Short and long-term shrinkage for the NWC, LWC and ILWC mixtures $(V / S=20 \mathrm{~mm})$.

\begin{tabular}{|c|c|c|c|c|c|c|}
\hline & \multicolumn{3}{|c|}{ 90-day shrinkage $(\mu \varepsilon)$} & \multicolumn{3}{|c|}{ Estimated ultimate shrinkage $(\mu \varepsilon)$} \\
\hline & NWC & LWC & ILWC & NWC & LWC & ILWC \\
\hline Measured & 550 & 710 & 897 & - & - & - \\
\hline $\mathrm{ACl}$ & 598 & 564 & 597 & 825 & 779 & 824 \\
\hline FIB2010 & 551 & 659 & 966 & 690 & 838 & 1228 \\
\hline $\mathrm{ACI}, \bar{\omega}_{\text {all }}[\%]$ & 37.2 & 28.4 & 32.7 & - & - & - \\
\hline FIB2010, $\bar{\omega}_{\text {all }}[\%]$ & 57.0 & 16.0 & 47.6 & - & - & - \\
\hline
\end{tabular}

Table 8

Short - and long-term shrinkage for the LWC and ILWC $(V / S=6.08 \mathrm{~mm})$.

\begin{tabular}{llllll}
\hline & \multicolumn{2}{l}{$\begin{array}{l}\text { 90-day shrinkage } \\
\text { estimate }(\mu \varepsilon)\end{array}$} & & \multicolumn{2}{l}{$\begin{array}{l}\text { Predicted ultimate } \\
\text { shrinkage }(\mu \varepsilon)\end{array}$} \\
\cline { 2 - 3 } \cline { 5 - 6 } & LWC & ILWC & & LWC & ILWC \\
\hline Measured & 959 & 1444 & & - \\
ACI & 634 & 671 & & 832 & 880 \\
FIB2010 & 812 & 1196 & & 839 & 1230 \\
ACI, Coef Var & 46.2 & 69.1 & & - & - \\
FIB2010, Coef Var & 28.4 & 41.1 & & - & - \\
\hline
\end{tabular}

and ILWC, respectively. Both models predicted the shrinkage of the normal concrete within $10 \%$ of error; thus, it can be stated that both models accurately predict the shrinkage of the NWC and that the measurements of both the LWC and ILWC samples are not biased.

Both models had similar performance when estimating the shrinkage of the LWC and ILWC. That is, on average, the ACI and FIB2010 models underestimated the shrinkage of the LWC by $14 \%$, while those same models underestimated the shrinkage of the ILWC by $13 \%$.

The coefficients of variation showed a better performance of the FIB2010 model compared to that of the ACI model for the LWC; however, the opposite occurred for the ILWC, where the ACI mod els had a lower coefficient of variation than that of the FIB 2010 model. Both the ACI and FIB2010 models had better performance predicting the shrinkage of the NWC at day 90 , with only $8.73 \%$ and $0.18 \%$ differences between the predicted and measured values, respectively. The higher variation coefficient in the FIB2010 model 
is due to the difference at early ages, mostly due to consideration of the basic shrinkage and other early age strains as opposed to the ACI model.

The better performance of the FIB2010 model regarding the LWC is attributed to the intensive model update for lightweight concrete with expanded clay done by Kvitsel. Interestingly, the model was also capable of predicting well the later measurements for the ILWC with expanded glass. This model uses the density and the lightweight concrete classification of the concrete to incorpo rate correction factors to the ultimate creep and shrinkage values.

A similar analysis was performed using the data from the smaller shrinkage specimens with a $\mathrm{V} / \mathrm{S}=6.08$. The lower $\mathrm{V} / \mathrm{S}$ increases water diffusion, accelerating drying and therefore drying shrinkage.

The comparisons among the experimental results and shrinkage model estimates of the LWC and ILWC mixtures are shown in Fig. 3.

As shown in Table 8, the best shrinkage estimates at 90 days and $V / S=6.08 \mathrm{~mm}$ for the LWC and ILWC are from the FIB2010 model. The FIB2010 model underestimated the measured shrink age values by only $15.3 \%$, and $17.2 \%$, for the LWC and ILWC, respec tively. From the variability point of view, the FIB2010 model, with a considerably lower coefficient of variation, also showed better performance than the ACI model.

Both models had better performance when estimating the shrinkage of the LWC compared with that of the ILWC. That is, on average, the ACI and FIB2010 models underestimated the shrinkage of the LWC by $25 \%$, while those same models underesti mated the shrinkage of the ILWC by $35 \%$.

It is noted that the performance of both models decreased when estimating the shrinkage of the smaller specimens $(\mathrm{V} / \mathrm{S}=6.08 \mathrm{~mm}$.) with respect to the larger specimens $(\mathrm{V} / \mathrm{S}=20 \mathrm{~mm}$.). That is, the underestimates at 90 days of approximately $14 \%$ obtained with $\mathrm{V} / \mathrm{S}=20 \mathrm{~mm}$ increased to $30 \%$ with $\mathrm{V} / \mathrm{S}=6.08 \mathrm{~mm}$. Something sim ilar occurred with the coefficients of variation, which increased from $31.1 \%$ for $\mathrm{V} / \mathrm{S}=20 \mathrm{~m}$ to 46.2 for $\mathrm{V} / \mathrm{S}=6.08 \mathrm{~mm}$.

This model performance decrease was even more noticeable for the ILWC than for the LWC. That is, the underestimates of $13 \%$ with $\mathrm{V} / \mathrm{S}=20 \mathrm{~mm}$ increased to $35 \%$ with $\mathrm{V} / \mathrm{S}=6.08 \mathrm{~mm}$, and the coefficients of variation increased from $40.2 \%$ with $\mathrm{V} / \mathrm{S}=20 \mathrm{~mm}$ to $55.1 \%$ with $\mathrm{V} / \mathrm{S}=6.08 \mathrm{~mm}$.

This model performance decrease might be related to the drying and water diffusion within the concrete, which are determined not only by the diffusion coefficient but also by the internal water contained in the lightweight aggregates.

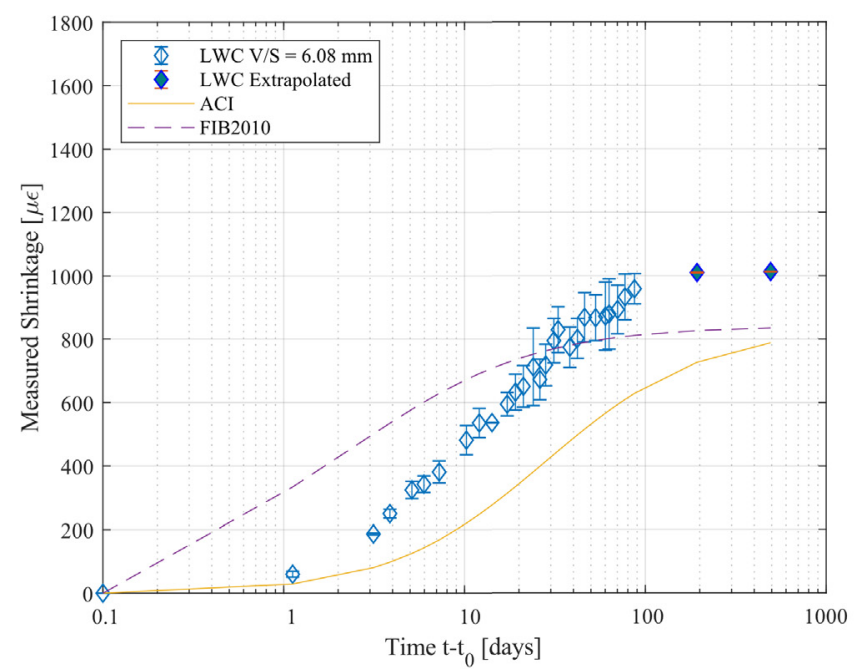

\subsection{Calibration methodology}

The calibration methodology is based on that proposed by Videla et al. [45]. The general form of the shrinkage and creep pre diction models can be expressed with the following equation:

$\varepsilon_{s h}^{\prime}\left(t, t_{0}\right) \quad \sum_{i}^{n} \varepsilon_{s h, i}^{\prime}\left(t, t_{0}\right) \quad \sum_{i}^{n} \prod_{j}^{k} K_{i, j} f_{i}^{\prime}\left(t, t_{0}\right) \varepsilon_{s h, \infty, i}^{\prime}$

where $\varepsilon_{s h}^{\prime}\left(t, t_{0}\right)$ is the total shrinkage at $t \quad t_{0}$ drying time, $t$ is the age of the concrete and $t_{0}$ is the curing time. The total shrinkage is comprised of the sum of each type of predicted shrinkage strain, $\varepsilon_{s h, i}^{\prime}\left(t, t_{0}\right)$ (basic shrinkage and drying shrinkage), depending on the model; $f_{i}^{\prime}\left(t, t_{0}\right)$ is the function that represents the shrinkage evolution for each type of shrinkage strain; $\varepsilon_{s h, \infty, i}^{\prime}$ is the constant value used to represent the ultimate shrinkage values; and $K_{i, j}$ are correction values adjusted by different factors that affect each type of shrinkage strain evolution, for instance, relative humidity, type of cement or supplementary cementing material and type of aggregate.

The need for model calibration is evaluated based on the com parison between the model predictions and experimental results. If a model has a coefficient of variation below $\pm 30 \%$, it is generally accepted that it is sufficiently accurate for design purposes [46] when the estimation is performed without having precise informa tion about the mixture, its mechanical properties, the environmen tal conditions or the materials used during mixing. Despite the fact that both models had a coefficient of variation below $30 \%$ for the LWC case, all the prediction models will be calibrated.

\subsection{Extrapolation}

For a more accurate calibration method, the ultimate shrinkage values should be extrapolated to represent the total shrinkage evo lution correctly. Nonetheless, it has been shown that short term data from just one specimen size is not sufficient for shrinkage extrapolation. Bažant and Donmez [38] proposed a promising method to extrapolate the ultimate shrinkage value based on short term shrinkage of specimens with different sizes $(\mathrm{V} / \mathrm{S})$. The extrapolation uses the diffusion theory effect on shrinkage, which has been proven to be a dominant factor in how shrinkage evolves as the specimen size changes. This is based on the following three physical requirements [38]:

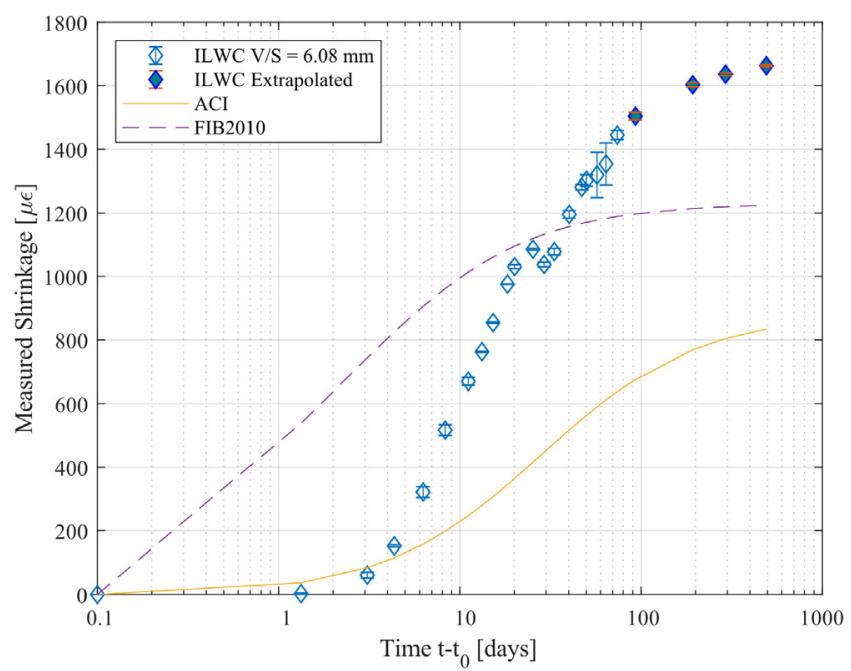

Fig. 3. Comparisons of the measured and model-estimated shrinkage of (a) LWC and (b) ILWC for V/S $=6.08 \mathrm{~mm}$. 
1. The shrinkage halftime must initially increase as $D^{2}$, where $D$ is the effective thickness of the specimen, being equal to $2 \mathrm{~V} / \mathrm{S}$, two times the volume to surface ratio.

2. $\varepsilon_{s h}$ must initially evolve as $\sqrt{ } t \quad t_{0}$

3. The approach to the final value must be asymptotically much closer to a decaying exponential than to a power law.

Therefore, the shrinkage curves of specimens from both sizes tend to be parallel and shifted by a distance $\Delta$ when plotted on a logarithmic scale as follows:

$\Delta \quad 2 \log \left(\frac{D_{1} k_{s, 1}}{D_{2} k_{s, 2}}\right)$

where $k_{s}$ is a correction factor ( 1 for an infinite slab, 1.15 for an infi nite cylinder and 1.25 for an infinite square prism).

Then, the proposed objective function to be minimized is as follows:

$$
\begin{aligned}
& \Phi(x, y) \quad w_{0} w_{1} \sum_{i}^{N}\left[\varepsilon_{1, i} \quad x \tanh \sqrt{\frac{t}{k_{s, 1}^{2} y D_{1}^{2}}}\right]^{2} \\
& +w_{2} \sum_{j}^{n}\left[\varepsilon_{m+1} \quad x \tanh \sqrt{\frac{t}{k_{s, 2}^{2} y D_{2}^{2}}}\right]^{2}+w_{3}\left[\|x\|_{2}+\|y\|_{2}\right]
\end{aligned}
$$

$w_{1} \quad \frac{1}{N} w_{2} \quad \frac{1}{n \quad m} x \quad \varepsilon_{s h, \infty} y \quad k_{1}$

where:

- $\varepsilon_{1, i}$, for $i \quad 1, \quad, N$ are the shrinkage values on $V / S=20 \mathrm{~mm}$ specimens.

- $\varepsilon_{2, j}$, for $j 1, \quad, m,, n$ are the shrinkage values on $V / S=6.08 \mathrm{~mm}$ specimens. Values between 1 and $m$ are not con sidered if $\epsilon_{2 j}<\varepsilon_{1 i}$, so the fit at early ages is not affected.

- $k_{1}$ or $y$ is the correction factor for the time function.

- $\varepsilon_{s h, \infty}$ or $x$ is the ultimate shrinkage value for the mix.

- $w_{1}$ and $w_{2}$ are bias countering weights for $V / S=20 \mathrm{~mm}$ and $V / S=6.08 \mathrm{~mm}$ size specimens, respectively, which ensure that both sums in the objective function have equal total weight.

- $w_{0}$ is an importance weight; in this case, 1 has been used.

- $\|x\|_{2}$ and $\|y\|_{2}$ are normalization functions incorporated into this extrapolation method. The main use of these functions is the restriction or regularization of possible solutions obtained by the optimization algorithm. $w_{3}$ is the weight, which is arbitrary (normally $10^{3}$ or $10^{4}$ ).

Using the nonlinear programming solver of MATLAB, which uses the simplex method of Lagarias et al. [47], the solution to Eq. (8) is shown in Table 9.

Using these parameters, we can build extrapolation functions with the following form:

$\boldsymbol{\varepsilon}_{\boldsymbol{s h}, \infty} \quad \boldsymbol{\varepsilon}_{\boldsymbol{s h}, \infty} \tanh \sqrt{\frac{t \quad t_{0}}{k_{s}^{2} k_{1} D^{2}}}$

that predict long term shrinkage values for the LWC and ILWC. The following figures show the extrapolation results (Fig. 4):

According to the extrapolations and regardless of the concrete type, the specimen size plays a relevant role in shrinkage. In fact, the difference in the magnitudes of the shrinkage between the two specimen sizes can be explained by the diffusion theory, as the loss of water occurs faster in the $\mathrm{V} / \mathrm{S}=6.08 \mathrm{~mm}$ (small) speci mens than in the $\mathrm{V} / \mathrm{S}=20 \mathrm{~mm}$ (large) specimens. This is mainly due to the greater slenderness of the $\mathrm{V} / \mathrm{S}=6.08 \mathrm{~mm}$ specimens,
Table 9

Extrapolation values obtained for EC and EG.

\begin{tabular}{lll}
\hline Mixture & $\boldsymbol{\varepsilon}_{\text {sh }, \infty}(\boldsymbol{\mu \varepsilon})$ & $\boldsymbol{k}_{1}$ \\
\hline LWC & 1015 & 0.059 \\
ILWC & 1631 & 0.129 \\
\hline
\end{tabular}

which makes it easier for water to leave to the environment compared to the $\mathrm{V} / \mathrm{S}=20 \mathrm{~mm}$ specimens.

According to the extrapolations with $\mathrm{V} / \mathrm{S}=20 \mathrm{~mm}$, the LWC reached $69.9 \%$ of the ultimate shrinkage value after 90 days of dry ing, while the ILWC reached only $55.0 \%$ of the ultimate shrinkage value. For the case with $\mathrm{V} / \mathrm{S}=6.08 \mathrm{~mm}$, the LWC reached $94.5 \%$ of the ultimate shrinkage value after 90 days of drying, while the ILWC reached only $88.5 \%$ of the ultimate shrinkage value. This means that regardless of the specimen size, the drying shrinkage develops slower in the ILWC than in the LWC, which can be related to the fact that the EG present in the ILWC is able to store more water than the EC present in the LWC as represented by their 72 hour absorptions of $48.5 \%$ for the EG and $20.9 \%$ for the EC.

\subsection{Model calibration}

For each model, Eq. (6) should be modified. For this, and follow ing the Videla, et al. [45] convention, $K_{g}$ and $K_{c}$ are defined as cor rection factors. $K_{g}$ is the correction factor for the ultimate shrinkage strain, while $K_{c}$ is the correction factor for the time func tion. In cases where the prediction models define the total shrink age as a sum of the basic and drying shrinkage strains, $K_{c}$ and $K_{g}$ will be independent for each time function. In this way, Eq. (6) now becomes the following:

$\varepsilon_{s h}^{\prime}\left(t, t_{0}\right) \quad \sum_{i}^{n} K_{g, i} \varepsilon_{s h, i}^{\prime}\left(t, t_{0}\right) \quad \sum_{i}^{n} \prod_{j}^{k} K_{i, j} f_{i}^{\prime}\left(K_{c, i}, t, t_{0}\right) K_{g, i} \varepsilon_{s h, \infty, i}^{\prime}$

In the following section, the modifications to the equations are summarized; these modifications do not include all the parameters of the models, and for the sake of simplicity, the ultimate shrinkage values already incorporate the correction factors. The definition of each constant and function can be viewed in more detail in each model $[11,19]$.

Shrinkage

ACI: Time Function Drying Shrinkage:

$f_{a c i}^{\prime}\left(K_{c}, t, t_{0}\right) \frac{t \quad t_{0}}{K_{c} \cdot k_{f c}+t \quad t_{0}}$

\section{Shrinkage:}

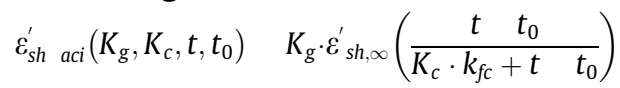

FIB2010:

Time Function Drying Shrinkage:

$f_{d s h f i b}^{\prime}\left(K_{c}, t, t_{0}\right) \quad \sqrt{\frac{t}{0.035 \cdot K_{c} \cdot\left(\frac{V}{S}\right)^{2}+t \quad t_{0}}}$

Time Function Basic Shrinkage:

$f_{b s h \text { fib }}^{\prime}\left(t, t_{0}\right) \quad e^{0.2 \sqrt{ } t_{0}} \quad e^{0.2 \sqrt{ } t} *$

* This time function is modified to have strain 0 at $t_{0}$ because basic shrinkage was not considered as a separate strain.

Total Shrinkage:

$$
\begin{aligned}
\varepsilon_{s h \text { fib }}^{\prime}\left(K_{g}, K_{c}, t, t_{0}\right) & K_{g, 1} \cdot \varepsilon_{d s h, \infty}^{\prime} \sqrt{\frac{t}{0.035 \cdot K_{c} \cdot\left(\frac{V}{S}\right)^{2}+t} t_{0}} \\
& +K_{g, 2} \cdot \varepsilon_{b s h, \infty}^{\prime}\left(e^{0.2 \sqrt{ } t_{0}} \quad e^{0.2 \sqrt{ } t}\right)
\end{aligned}
$$



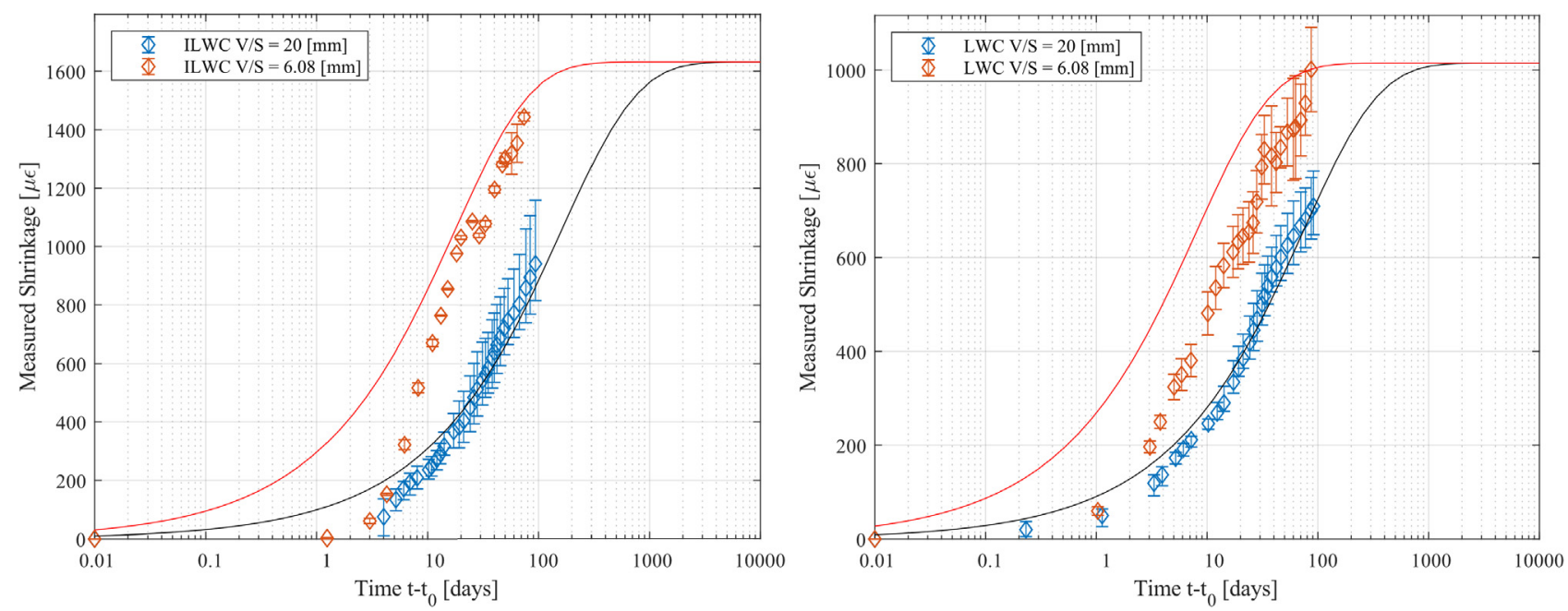

Fig. 4. Extrapolation results for (a) LWC and (b) ILWC.

\subsection{Objective function}

Having composed the calibrated functions, the following objec tive function is defined:

$\Phi\left(K_{g, 1}, \ldots, K_{c}\right) \quad \sum_{i=1}^{n} w_{1}\left\|\varepsilon_{i}(t) \quad \varepsilon_{s h}^{\prime}\left(K_{g, 1}, \cdots, K_{c}, t, t_{0}\right)\right\|_{2}+w_{0} \sqrt{ } \widehat{K} \cdot \widehat{K}^{t}$

$\widehat{K} \quad\left\langle\begin{array}{lll}K_{g, 1} & \cdots & K_{c}\end{array}\right.$

where $\widehat{K}$ is the calibration correction factor vector, which is the norm used for normalization of the solutions; $\varepsilon_{s h}^{\prime}$ is the prediction function with calibration correction factors; $w_{1}$ is the weight function defined in Eq. (3), which in this case is used to force the ultimate shrinkage corresponding to that previously extrapolated; and $w_{0}$ is an arbitrary constant for normalization purposes $\left(10^{3}\right.$ or $\left.10^{4}\right)$.

Using the nonlinear programming solver of MATLAB, which uses the simplex method of Lagarias et al. [47], the models are calibrated by minimizing the objective function (17).

\subsection{Calibration results and discussion}

After calibrating the models with the above described proce dure, a statistical analysis was performed to evaluate the perfor mance of the calibration performed on all the prediction models. The obtained calibration correction factors are shown in Table 10.

The calibration correction factor applied to the ultimate shrink age value $\left(K_{g}\right)$ strongly depends on the concrete type (NWC, LWC or ILWC) and on the model itself (ACI or FIB2010).

When analyzing the ultimate shrinkage values, the best perfor mance was obtained for the NWC using the ACI model, which had a $K_{g}$ almost equal to 1.0. The ACI model underestimated the ultimate shrinkage of the LWC with $K_{g}$ values of 1.29 and 1.26 for $\mathrm{V} / \mathrm{S}=20 \mathrm{~mm}$ and $6.08 \mathrm{~mm}$, respectively. The same model underes timated the ultimate shrinkage of the ILWC having $K_{g}$ of 1.97 and 1.95 for $\mathrm{V} / \mathrm{S}=20 \mathrm{~mm}$ and $6.08 \mathrm{~mm}$, respectively. Therefore, the $\mathrm{ACI}$ model provided accurate estimates for the ultimate shrinkage of the NWC, underestimated that of the LWC by nearly $22 \%$ and greatly underestimated the ultimate shrinkage of the ILWC by nearly $50 \%$.
Table 10

Model calibration correction factors.

\begin{tabular}{|c|c|c|c|c|c|c|}
\hline \multirow[t]{2}{*}{$\mathrm{V} / \mathrm{S}(\mathbf{m m})$} & \multirow[t]{2}{*}{ Mixture } & \multicolumn{2}{|l|}{ ACI } & \multicolumn{3}{|c|}{ FIB2010 } \\
\hline & & $K_{g}$ & $K_{c}$ & $K_{g, 1}$ & $K_{g, 2}$ & $K_{c}$ \\
\hline 20 & NWC & 1.03 & 1.49 & 1.48 & 0.14 & 2.90 \\
\hline 20 & LWC & 1.29 & 0.98 & 1.27 & 1.37 & 2.21 \\
\hline 20 & ILWC & 1.97 & 2.03 & 1.32 & 0.55 & 2.99 \\
\hline 6.08 & LWC & 1.26 & 0.29 & 1.22 & 1.42 & 1.15 \\
\hline 6.08 & ILWC & 1.95 & 0.47 & 1.32 & 1.47 & 2.58 \\
\hline
\end{tabular}

Overall, the FIB2010 model had a better prediction of the ultimate shrinkage values of the LWC, mainly due to the correction improvements performed by Kvitsel, which correct the final shrinkage value according to the density and compressive strength category for the LWC $[8,11]$. Interestingly, the correction factor $K_{g, 1}$, which accounts for drying shrinkage in the FIB2010 model, had similar values for both specimens of both mixtures (1.22 1.32), but measurements of sealed specimens should be performed to more accurately account for the effects of basic shrinkage, which for the LWC and ILWC is an important factor. Overall, the FIB2010 model underestimated the ultimate shrinkage of the NWC by nearly $32 \%$, underestimated that of the LWC by nearly $20 \%$ and greatly underestimated the ultimate shrinkage of the ILWC by nearly $24 \%$.

When analyzing the evolution of shrinkage, it can be concluded that the ACI model had a better prediction of the evolution of shrinkage strains than the FIB2010 model, as shown by the lower $K_{c}$ obtained by the ACI model for the three types of concrete (NWC, LWC and ILWC) and the two specimen sizes (V/S = $20 \mathrm{~mm}$ and $6.08 \mathrm{~mm}$ ). This might be explained based on the FIB time evolution function as $\sqrt{ } t \quad t_{0}$ and proportional to $(2 \mathrm{~V} / \mathrm{S})^{2}$, which may be the case for the NWC with low permeability and without internally stored water in the aggregates. However, in the concrete mixtures containing prewetted LWA, the internal curing plays an important factor, as previously concluded for concrete of similar W/C under drying shrinkage $[48,49]$.

Additionally, when comparing $K_{c}$ between the three types of concretes, it can be observed that the $K_{c}$ of the ILWC was always larger than that of the LWC for the two models and the two spec imen sizes; also the $K_{c}$ of the LWC was always larger than that of the NWC. This means that the presence of the LWA delays shrink age, so the models need to be corrected using larger values of $K_{c}$. Specifically, EG delays shrinkage even more than EC, which can 
Table 11

Coefficient of determination $\mathrm{R}^{2}$ and coefficient of variation $\bar{\omega}_{\text {all }}$ as defined by Bažant, after calibration.

\begin{tabular}{|c|c|c|c|c|c|}
\hline \multirow[t]{2}{*}{$\mathrm{V} / \mathbf{S}(\mathbf{m m})$} & \multirow[t]{2}{*}{ Mixture } & \multicolumn{2}{|l|}{ ACI } & \multicolumn{2}{|c|}{ FIB2010 } \\
\hline & & $\mathrm{R}^{2}$ & $\bar{\omega}_{\text {all }}[\%]$ & $\mathrm{R}^{2}$ & $\bar{\omega}_{\text {all }}[\%]$ \\
\hline 20 & NWC & 0.985 & 19.97 & 0.810 & 35.66 \\
\hline 20 & LWC & 0.991 & 9.7 & 0.940 & 12.0 \\
\hline 20 & ILWC & 0.988 & 10.0 & 0.734 & 30.1 \\
\hline 6.08 & LWC & 0.905 & 18.5 & 0.212 & 42.7 \\
\hline 6.08 & ILWC & 0.928 & 16.1 & 0.443 & 44.3 \\
\hline
\end{tabular}
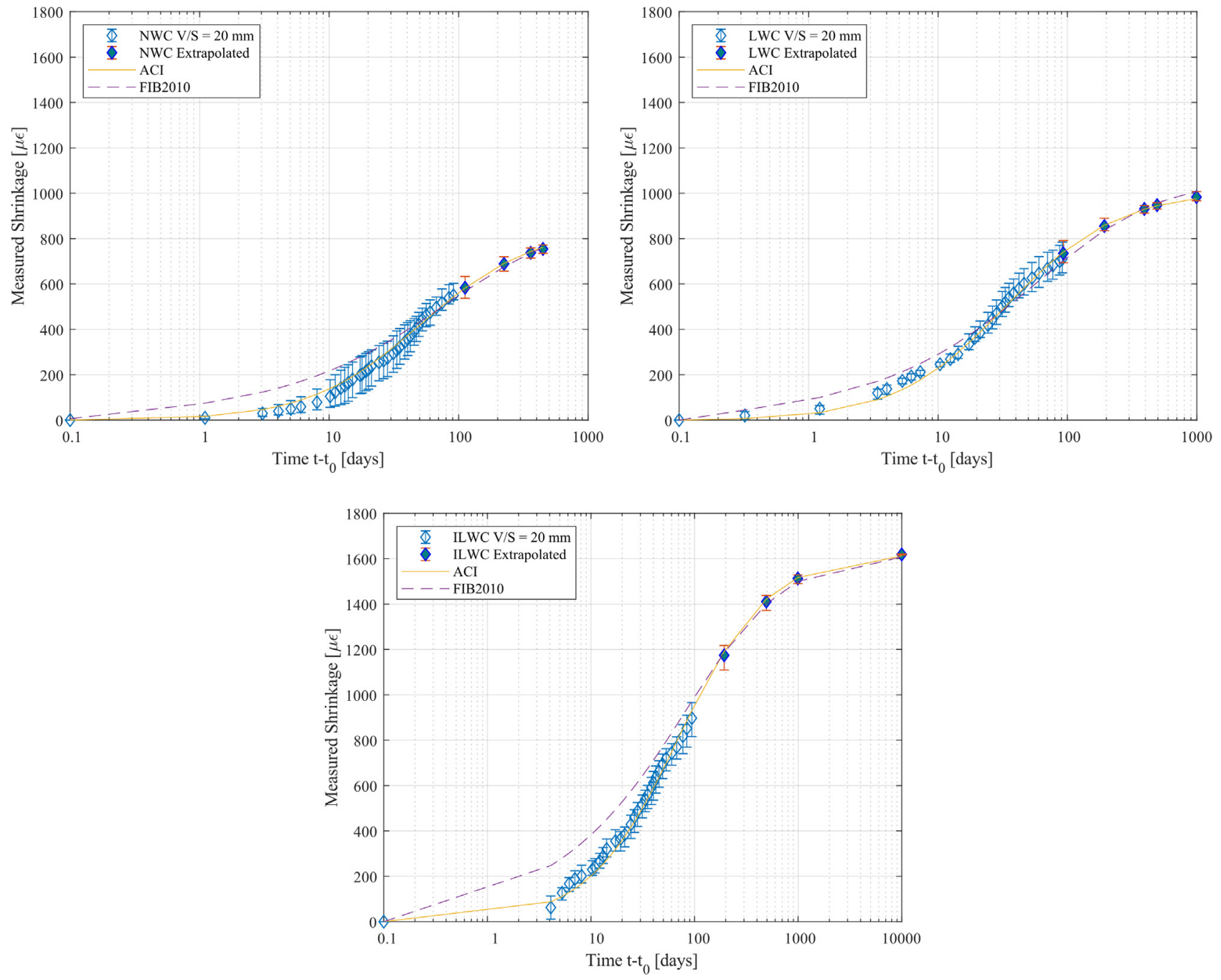

Fig. 5. Comparisons of the measured and calibrated model-estimated shrinkage of (a) NWC, (b) LWC and (c) ILWC for V/S $=20 \mathrm{~mm}$.

be related to the water absorbed in the LWA at the time of mixing $[48,50]$. That is, the more water that is contained within the LWA, the greater the shrinkage delay.

The movement water from the LWA (internal curing) may also explain the differences in the shrinkage strain evolution between the two specimen sizes. Water loss from the LWA was lower in $\mathrm{V} / \mathrm{S}=20 \mathrm{~mm}$ specimens than in $\mathrm{V} / \mathrm{S}=6.08 \mathrm{~mm}$ specimens. There fore, the internal curing effect was more relevant in the $\mathrm{V} / \mathrm{S}=20 \mathrm{~mm}$ specimens, leading to more effective hydration of the cement paste; this will lead to lower porosity and permeability of the hydrated cement paste and therefore lower water diffusion, as observed previously [51].

The statistical analysis involved the coefficient of determination $R^{2}$ and coefficient of variation, $\bar{\omega}_{\text {all }}$ as shown in Table 11 .
The performance of the calibrated models improved overall. The ACI model is the best prediction model after calibration, having larger $\mathrm{R}^{2}$ and lower $\bar{\omega}_{\text {all }}$ for the LWC and ILWC, except for the case of the LWC with V/S $=20 \mathrm{~mm}$ specimens where the FIB2010 model had a larger $R^{2}$. It should be noted that the FIB2010 model performed poorly even after calibration for the $\mathrm{V} / \mathrm{S}=6.08 \mathrm{~mm}$ specimens for both the LWC and ILWC; this could be related to the internal curing effect mentioned earlier.

\subsection{Calibration validation}

The calibrated models were validated against the experimental data from this study (See Fig. 5), in order to assess the improvements in the estimates when compared to the original models (See Fig. 3). 

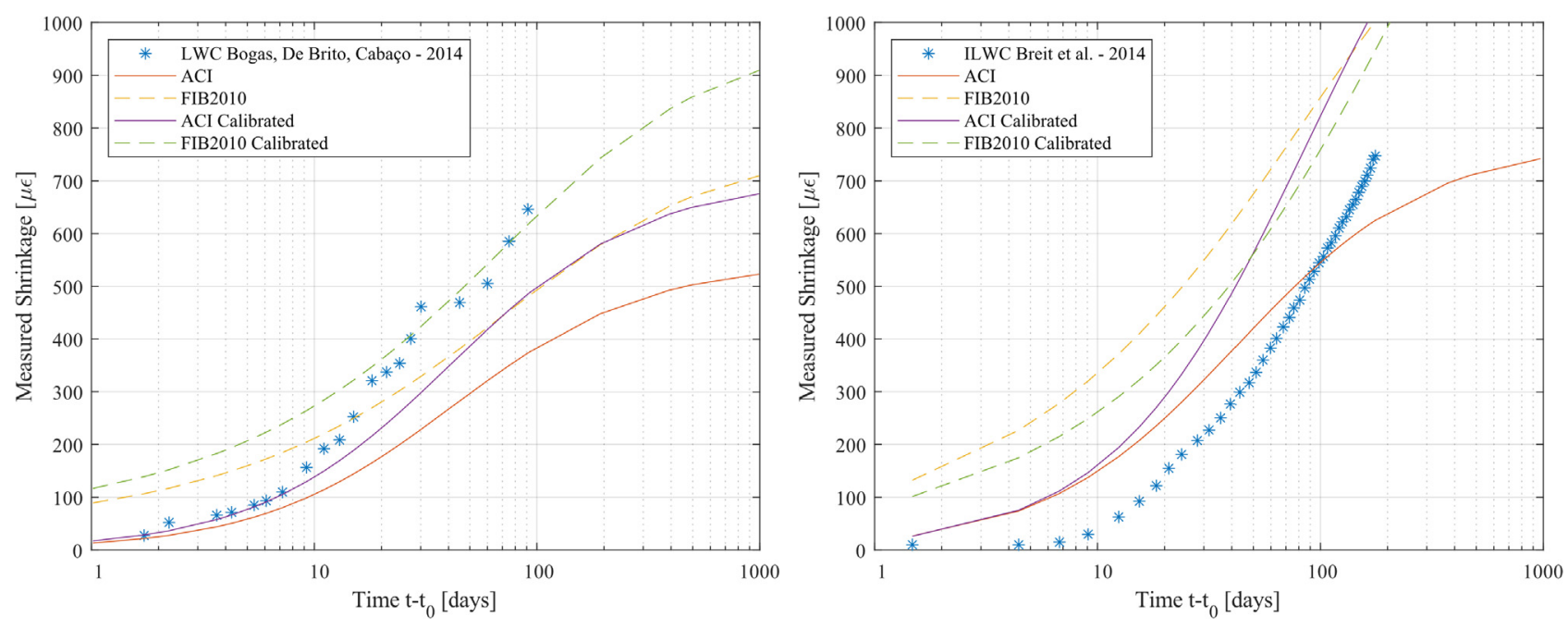

Fig. 6. Comparisons of the measured and calibrated model-estimated shrinkage of (a) LWC and (b) ILWC for V/S $=20 \mathrm{~mm}$.

As expected, the calibrated models predict accurately the drying shrinkage of NWC, LWC and ILWC. This is clear when comparing the original performance of the models prior to calibration shown in Fig. 3.

Moreover, the calibrated ACI models performed better than the calibrated FIB2010 model especially for NWC and ILWC where the calibrated FIB2010 model tends to overestimate shrinkage during the first few weeks.

Further validation of the calibrated models was performed by comparing the new estimates against the experimental data, but using new data from other studies found in the literature (See Fig. 6) which were not used in the calibration process. The calibra tion values detailed in Table 10 were then used for using the calibrated models for predicting the shrinkage of LWC and ILWC of similar composition dried in comparable environmental condi tions [52,53].

In the case of the LWC data [53] shown in Fig. 6a, the calibration clearly improved the estimates of both models especially after 14 days of drying. Calibrated FIB2010 models performed better than the calibrated ACI model.

In the case of the ILWC data [52] shown in Fig. 6b, the calibra tion improved the estimates of the FIB2010 model, but made worse those of ACI. Both models overestimated the Shrinkage of ILWC especially during the first few weeks. Calibrated FIB2010 models performed better than the calibrated ACI model.

Overall, the calibrated models can predict reasonably well the shrinkage, even though the drying conditions, curing and specimen sizes vary. A more extensive research in regards of these variables should be done for the impact of these variables on shrinkage of LWC and ILWC.

The calibrated models would need to be further corrected if new LWAs different from EC and EG are considered. This is mainly due to the fact that the models do not include specific properties of the LWAs such as porosity, pore size distribution, and the mechan ical properties of the solid phase of the LWA.

\section{Conclusions}

Shrinkage was experimentally measured and analytically modeled for three types of concrete: normal weight concrete (NWC) with normal weight aggregates, lightweight concrete (LWC) with expanded clay (EC) lightweight aggregate (LWA) and infra lightweight concrete (ILWC) with expanded glass (EG) LWA. Concrete specimens were stored at $22( \pm 1){ }^{\circ} \mathrm{C}$ and $50( \pm 3) \% \mathrm{R}$. H. for a period of 90 days of drying. The compressive strength at 7 days of age of the NWC, LWC, and ILWC was 40.5, 20.6, and $10.1 \mathrm{MPa}$, respectively.

The experimental results from shrinkage were compared against the ACI and FIB2010 prediction models. Both models estimated shrinkage of the NWC within $10 \%$ of error and underestimated the shrinkage of the LWC and ILWC by approximately $14 \%$. Both models were adjusted to better represent the experimental values using a calibration methodology involving $K_{g}$ and $K_{c}$ as calibration factors for ultimate shrinkage and the evolution of shrinkage.

After calibration, the FIB2010 model had an overall better prediction of the final shrinkage values of the LWC mainly due to the correction improvements performed by Kvitsel, thus having smaller $K_{g}$ values, which accounts for the density, and thus poros ity, of the LWC and ILWC. However, the ACI model, as shown by its lower $K_{c}$ values, had a better prediction of the evolution of shrink age than the FIB2010 model. This shows that the prewetted LWA slowed the shrinkage evolution.

The performance of the calibrated models improved overall. Nevertheless, the ACI model obtained better performance than the FIB2010 model for the two sets of data used in this investiga tion; this was mainly due to the time function for shrinkage evolution of the ACI model that better suits the experimental shrinkage evolution of concretes containing prewetted LWA providing internal curing.

The calibration with this limited set of data proved to be useful to estimate shrinkage of LWC and ILWC mixtures that were not part of the data base used for the original shrinkage model devel opment. Further extensive work needs to be carried out to keep updating the model codes in the future.

\section{CRediT authorship contribution statement}

Sebastián Labbé: Conceptualization, Data curation, Formal analysis, Investigation, Methodology, Validation, Writing original draft, Writing review \& editing. Mauricio Lopez: Conceptualiza tion, Formal analysis, Resources, Supervision, Writing original draft, Writing review \& editing.

\section{Declaration of Competing Interest}

The authors declare that they have no known competing finan cial interests or personal relationships that could have appeared to influence the work reported in this paper. 


\section{Acknowledgments}

This work was funded by research CONICYT/FONDEF D10I1086 Chile and supported by CEDEUS, CONICYT/FONDAP 15110020 Chile. In addition, the authors greatly appreciate the help of Mario Olivares, Claudio Valdés and the whole staff of DICTUC for the use of the drying chamber and instruments; Cristian Imbarack of BSA for providing the Portland cement; Mauricio Guerra from the materials laboratory; and Sergio Vera and Jose Carlos Remesar gave important feedback during the investigation. The authors also acknowledge the German Academic Exchange Service (DAAD) for their founding; Dr. Bou Young Young and Professor Rolf Breit enbücher of the Building Materials Laboratory at Ruhr University Bochum; and Dr. Michael Vogel, Professor Harald Müller and Dr. Vladislav Kvitsel of the Materials Testing and Research Institute at Karlsruher Institute of Technology.

\section{References}

[1] J.C. Remesar, S. Vera, M. Lopez, Assessing and understanding the interaction between mechanical and thermal properties in concrete for developing a structural and insulating material, Constr. Build. Mater. 132 (2017) 353-364, https://doi.org/10.1016/j.conbuildmat.2016.11.116.

[2] M. Lopez, L.F. Kahn, K.E. Kurtis, Creep and shrinkage of high-performance lightweight concrete, ACI Mater. J. 101 (2004) 391-399.

[3] W. Breit, J. Schulze, C. Heese, B. Bund, Highly insulating, monolithic concrete panels made of architectural lightweight concrete, Kaiserslautern, 2014. https://www.irbnet.de/daten/kbf/kbf_e_F_2894.pdf\%0A.

[4] R. Nemes, Lightweight Concrete made with Expanded Glass Aggregate, Budapest University of Technology and Economics, 2006.

[5] M. Zareef, Conceptual and structural design of infra-lightweight concrete, Technical, University of Berlin, 2010.

[6] A. Enshassi, H. Al Ghoul, S. AlKilani, Exploring sustainable factors during construction projects' life cycle phases, Rev. Ing. Constr. 33 (2018) 51-68.

[7] J.A. Browning, D. Darwin, D. Reynolds, B. Pendergrass, Lightweight aggregate as internal curing agent to limit concrete shrinkage, ACI Mater. J. 108 (2011) 638-644.

[8] V. Kvitsel, Zur Vorhersage des Schwindens und Kriechens von normal- und hochfestem Konstruktionsleichtbeton mit Blähtongesteinskörnung, KIT Scientific Publishing, Karlsruhe, Karlsruhe (2017), https://doi.org/10.5445/ KSP/1000054333.

[9] X.F. Wang, Y.J. Huang, G.Y. Wu, C. Fang, D.W. Li, N.X. Han, F. Xing, Effect of nano-SiO2 on strength, shrinkage and cracking sensitivity of lightweight aggregate concrete, Constr. Build. Mater. 175 (2018) 115-125, https://doi.org/ 10.1016/j.conbuildmat.2018.04.113.

[10] K. Gorospe, E. Booya, H. Ghaednia, S. Das, Effect of various glass aggregates on the shrinkage and expansion of cement mortar, Constr. Build. Mater. 210 (2019) 301-311, https://doi.org/10.1016/j.conbuildmat.2019.03.192.

[11] fib, fib Model Code for Concrete Structures 2010, Wiley-VCH Verlag GmbH \& Co. KGaA, Weinheim, Germany, 2013. https://doi.org/10.1002/9783433604090.

[12] K. Walz, G. Wischers, Konstruktions-Leichtbeton hoher Festigkeit. Stand der Entwicklung in den USA am Beispiel von Blähtonzuschlag aus dem Drehofen, Forschungsinstitut der Zementindustrie, Düsseldorf, Germany, 1964.

[13] T. Faust, Leichtbeton im Konstruktiven Ingenieurbau, Beton- Und Stahlbetonbau. 98 (2003) A23-A24, https://doi.org/10.1002/best 200301640.

[14] G. Espinoza-Hijazin, Á. Paul, M. Lopez, Concrete Containing Natural Pozzolans: New Challenges for Internal Curing, J. Mater. Civ. Eng. 24 (2012) 981-988, https://doi.org/10.1061/(ASCE)MT.1943-5533.0000421.

[15] L.F. Kahn, M. Lopez, Prestress losses in high performance lightweight concrete pretensioned bridge girders, PCI J. 50 (2005) 84-+.

[16] A. Katz, A. Bentur, K.O. Kjellsen, Normal and High Strength Concretes with Lightweight Aggregates, in: M.G. Alexander, G. Arliguie, G. Ballivy, A. Bentur, J. Marchand (Eds.), RILEM Rep. 20 Eng. Transp. Prop. Interfacial Transit. Zo. Cem. Compos., RILEM Publications S.A.R.L., Cachan, France, 1999: pp. 71-88.

[17] J. Liu, C. Shi, X. Ma, K.H. Khayat, J. Zhang, D. Wang, An overview on the effect of internal curing on shrinkage of high performance cement-based materials, Constr. Build. Mater. 146 (2017) 702-712, https://doi.org/10.1016/ j.conbuildmat.2017.04.154.

[18] T. Ji, D.D. Zheng, X.F. Chen, X.J. Lin, H.C. Wu, Effect of prewetting degree of ceramsite on the early-age autogenous shrinkage of lightweight aggregate concrete, Constr. Build. Mater. 98 (2015) 102-111, https://doi.org/10.1016/ j.conbuildmat.2015.08.102.

[19] ACI Committee 209 (ACI 209.2R-08), Guide for Modeling and Calculating Shrinkage and Creep in Hardened Concrete, American Concrete Institute, Farmington Hills, MI, 2008.

[20] ACI Committee 213 (ACI 213R-03), Guide for Structural LightweightAggregate Concrete, American Concrete Institute, Farmington Hills, MI, 2003.
[21] Y. Ke, S. Ortola, A.L. Beaucour, H. Dumontet, Identification of microstructural characteristics in lightweight aggregate concretes by micromechanical modelling including the interfacial transition zone (ITZ), Cem. Concr. Res. 40 (2010) 1590-1600, https://doi.org/10.1016/j.cemconres.2010.07.001.

[22] M.H. Zhang, O.E. Gjørv, Microstructure of the Interfacial Zone between Lightweight Aggregate and Cement Paste, Cem. Concr. Res. 20 (1990) 610-618.

[23] B.F. Dela, H. Stang, Two-dimensional analysis of crack formation around aggregates in high-shrinkage cement paste, Eng. Fract. Mech. 65 (2000) 149-164, https://doi.org/10.1016/S0013-7944(99)00113-7.

[24] P. Grassl, H.S. Wong, N.R. Buenfeld, Influence of aggregate size and volume fraction on shrinkage induced micro-cracking of concrete and mortar, Cem. Concr. Res. 40 (2010) 85-93, https://doi.org/10.1016/j.cemconres.2009.09.012.

[25] J.-H.H. Moon, F. Rajabipour, B. Pease, J. Weiss, Autogenous shrinkage, residual stress, and cracking in cementitious composites: The influence of internal and external restraint, Fourth Int. Semin. Self-Desiccation Its Importance Concr. Technol. (2005) 1-20. http://bridge.ecn.purdue.edu/ concrete/weiss/ publications/r_conference/RC-036.pdf.

[26] M. Lopez, Creep and Shrinkage of High Performance Lightweight Concrete : a Multi-Scale Investigation Creep and Shrinkage of High Performance Lightweight Concrete : a Multi-Scale Investigation, Environ. Eng. (2005). http://etd.gatech.edu/theses/available/etd-11222005-122831/.

[27] A.M. Neville, Properties of concrete, 5th ed., Pearson, Harlow, Sussex, 2011.

[28] ASTM, C1761 / C1761M-15, Standard Specification for Lightweight Aggregate for Internal Curing of Concrete, ASTM International, West Conshohocken, PA, 2013. https://doi.org/10.1520/C1761.

[29] Hormigones Bicentenario S.A., Aspectos Técnicos Cemento Portland BSA (2016) $1-2$

[30] C. Videla, M. Lopez, Mixture proportioning methodology for structural sandlightweight concrete, ACI Struct. J. 97 (2000) 281-289.

[31] ASTM Standard C192/C192M - 16a, Standard Practice for Making and Curing Concrete Test Specimens in the Laboratory, ASTM International, West Conshohocken, PA, 2016. https://doi.org/10.1520/C0192_C0192M-16A.

[32] ASTM Standard C39/C39M - 17a, Standard Test Method for Compressive Strength of Cylindrical Concrete Specimens, ASTM International, West Conshohocken, PA, 2017. https://doi.org/10.1520/C0039_C0039M-17A.

[33] ASTM Standard C469/C469M - 14, Standard Test Method for Static Modulus of Elasticity and Poisson's Ratio of Concrete in Compression, ASTM International, West Conshohocken, PA, 2014. https://doi.org/10.1520/C0469-02E01.2.

[34] ASTM Standard C215 - 14, Standard Test Method for Fundamental Transverse, Longitudinal, and Torsional Resonant Frequencies of Concrete Specimens, ASTM International, West Conshohocken, PA, 2014. https://doi.org/10.1520/ C0215-14.2.

[35] R.P. Spragg, J. Castro, T. Nantung, M. Paredes, J. Weiss, Variability Analysis of the Bulk Resistivity Measured Using Concrete Cylinders, Adv. Civ. Eng. Mater. 1 (2012) 16, https://doi.org/10.1520/ACEM104596.

[36] ASTM Standard C567/C567M - 14, Standard Test Method for Determining Density of Structural Lightweight Concrete, ASTM International, West Conshohocken, PA, 2014. https://doi.org/10.1520/C0567-05A.2.

[37] ASTM Standard C596 - 01, Standard Test Method for Drying Shrinkage of Mortar Containing Hydraulic Cement, ASTM International, West Conshohocken, PA, 2001. https://doi.org/10.1520/C0596-09.

[38] Z.P. Bažant, A. Donmez, Extrapolation of short-time drying shrinkage tests based on measured diffusion size effect: concept and reality, Mater. Struct. 49 (2016) 411-420, https://doi.org/10.1617/s11527-014-0507-0.

[39] D. Kocáb, M. Králíková, P. Cikrle, P. Misák, B. Kucharczyková, Experimental analysis of the influence of concrete curing on the development of its elastic modulus over time, Mater. Tehnol. 51 (2017) 657-665. https://doi.org/10. $17222 /$ mit.2016.248.

[40] D. Kocab, B. Kucharczykova, P. Misak, P. Zitt, M. Kralikova, Development of the Elastic Modulus of Concrete under Different Curing Conditions, Procedia Eng. 195 (2017) 96-101, https://doi.org/10.1016/j.proeng.2017.04.529.

[41] M. Golias, D. Bentz, J. Weiss, Influence of Exposure Conditions on the Efficiency of Internal Curing, Adv. Civ. Eng. Mater. 2 (2013) 522-533, https://doi.org/ 10.1520/ACEM20120023.

[42] G.J.L. van der Wegen, J.M.J.M. Bijen, Properties of concrete made with three types of artificial PFA coarse aggregates, Int. J. Cem. Compos. Light. Concr. 7 (1985) 159-167, https://doi.org/10.1016/0262-5075(85)90003-X.

[43] A. Wedding, F. Wittmann, Z. Bazant, F. Alou, J.-K. Kim, Statistics of Shrinkage Test Data, Cem. Concr. Aggregates. 9 (1987) 129, https://doi.org/10.1520/ CCA10078J.

[44] Z.P. Bažant, S. Baweja, Justification and refinements of model B3 for concrete creep and shrinkage 1. Statistics and sensitivity, Mater. Struct. 28 (1995) 488495, https://doi.org/10.1007/BF02473171.

[45] C. Videla, J.P. Covarrubias, C. Masana, Calibration of Drying Shrinkage Prediction Models for Chilean Cement Concretes, Rev. Ing. Construcción. 16 (2001) 1-19.

[46] ACI Committee 209 (ACI 209-R92), Chapter 5: Modeling and Calculation of Shrinkage, Creep and Thermal Expansion, ACI 209 Comm. Intern. Discuss. Doc. (1999).

[47] J.C. Lagarias, J.A. Reeds, M.H. Wright, P.E. Wright, Convergence Properties of the Nelder-Mead Simplex Method in Low Dimensions, SIAM J. Optim. 9 (1998) $112-147$.

[48] J.G. Guðmundsson, Long-term creep and shrinkage in concrete using porous aggregate - The effects of elastic modulus, Reykjavík University, 2013.

[49] G. Espinoza-Hijazin, M. Lopez, Extending internal curing to concrete mixtures with W/C higher than 0.42, Constr. Build. Mater. 25 (2011) 1236-1242, https:// doi.org/10.1016/j.conbuildmat.2010.09.031. 
[50] M. Lopez, L. Kahn, K.E. Kurtis, Effect of internally stored water on creep of highperformance concrete, ACI Mater. J. 105 (2008) 265-273.

[51] S. Zhutovsky, K. Kovler, Effect of internal curing on durability-related properties of high performance concrete, Cem. Concr. Res. 42 (2012) 20-26 https://doi.org/10.1016/j.cemconres.2011.07.012.
[52] W. Breit, J. Schulze, C. Heese, B. Bund, Hochwärmedämmende, monolithische Sichtbetonaußenteile aus Architekturleichtbeton, Bonn, Germany, 2014.

[53] J.A. Bogas, J. De Brito, J. Cabaço, Long-term behaviour of concrete produced with recycled lightweight expanded clay aggregate concrete, Constr. Build. Mater. 65 (2014) 470-479. https://doi.org/10.1016/j.conbuildmat.2014.05.003. 


\section{Repository KITopen}

Dies ist ein Postprint/begutachtetes Manuskript.

Empfohlene Zitierung:

Labbé, S.; Lopez, M.

Towards a more accurate shrinkage modeling of lightweight and infra-lightweight concrete. 2020. Construction and building materials, 246.

doi: $10.554 / I R / 1000124812$

Zitierung der Originalveröffentlichung:

Labbé, S.; Lopez, M.

Towards a more accurate shrinkage modeling of lightweight and infra-lightweight concrete. 2020. Construction and building materials, 246, Art.-Nr.: 118369.

doi:10.1016/j.conbuildmat.2020.118369 